\title{
Effects of modafinil on pentylenetetrazol-induced convulsive epilepsy
}

\author{
Ozsoy $\mathrm{S}^{1}$, Aydin $\mathrm{D}^{2}$, Ekici F ${ }^{3}$ \\ Gaziosmanpasa University Faculty of Medicine, Department of Physiology, Tokat, Turkey. \\ seyma.ozsoy@hotmail.com
}

\begin{abstract}
Modafinil, is a wake-promoting drug approved by Food and Drugs Administration (FDA) for narcolepsy and sleep-apnoe syndrome. Although the mechanism underlying its arousal action remains elusive, it is known to increase glutamatergic, histaminergic, noradrenergic and dopaminergic transmission and decrease GABA release in different regions of the brain, which are all known to be involved in pathophysiology of epilepsy. In the present study, the effects of modafinil on pentylenetetrazol (PTZ) induced convulsive epilepsy were investigated in rats. Five experimental groups were formed for this purpose and each group was administered five different doses of modafinil $(1,2,4,45,180 \mathrm{mg} / \mathrm{kg}$, i.p) for seven days. All groups were administered PTZ (80 $\mathrm{mg} / \mathrm{kg}$, i.p) 2 hours after the final dose and the epileptic seizure activity was evaluated. According to the results; we detected that modafinil delayed the onset of the first myoclonic jerk and decreased the total major seizure period between 2-180 mg/kg doses and did not affect the major seizure onset period at any of the doses administrated. These results imply that modafinil exerts a dose dependent antiepileptic effect on PTZ induced convulsive epilepsy in rats (Tab. 1, Fig. 3, Ref, 42). Text in PDF www.elis.sk.

Key words: modafinil, pentylenetetrazol, experimental epilepsy.
\end{abstract}

\section{Introduction}

Epilepsy is a serious neurobehavioral disorder characterized by recurrent seizures, presenting with episodes of sensory, motor or autonomic symptoms with or without loss of consciousness (Sridharan, 2002). Epileptogenesis is closely related to an imbalance between GABAergic and glutamatergic activity in different regions of the brain (Dalby et al, 2001). Impairment of GABAmediated inhibitory and glutamate-mediated excitatory circuits has been implicated in different forms of epilepsy in experimental animal models and in human studies. On the other hand, epilepsy has a complex association with sleep. Most of the epilepsy patients complain from sleep disturbance and also sedative and cognitive adverse effects of the antiepileptic drugs. A large number of experimental models of seizure and epilepsy have been developed to understand basic mechanisms underlying epileptogenesis (Bambal et al, 2011). Pentylenetetrazol (PTZ) is a systemic convulsive agent, which is generally used to form experimental epilepsy models. It is the selective GABA-A receptor channel blocker and is related with decrease of GABA- mediated neurotransmission (Bambal et al, 2011). In low doses, it induces typical changes in the EEG characterised by short-lasting trains of spike and waves at $5 \pm 7$ $\mathrm{Hz}$ frequency with no clear overt behavioural response. In higher

${ }^{1}$ Gaziosmanpasa University Faculty of Medicine, Department of Physiology, Tokat, Turkey, ${ }^{2}$ Fatih University Faculty of Medicine, Department of Physiology, Ankara, Turkey, and ${ }^{3}$ Yildirim Beyazit University Faculty of Medicine, Department of Physiology, Ankara, Turkey

Address for correspondence: S. Ozsoy, MSc, Gaziosmanpasa University, Faculty of Medicine, Department of Physiology, Tokat, Turkey.

Phone: +90.356.2129500, Fax: +90.356.2133179
(> $40 \mathrm{mg} / \mathrm{kg}$; ip) doses, however, PTZ induces clear behavioural responses (Klioueva et al, 2000). Behavioural scoring is commonly used to access seizure intensity in PTZ model of epilepsy.

Modafinil, (RS)-2-(Diphenylmethylsulfinyl)acetamide, a well known wake promoting drug, has been in use of daytime sleepiness in the patients of narcolepsy for a few years. It improves wakefulness in a variety of species and is efficacious in humans with few peripheral or central side effects. Modafinil is theorised to work in a localised manner. The mechanisms underlying its clinical effects are complex and not similar with the other wake-promoting agents. Researchers have not been able to isolate a specific site of action or locate a major receptor binding. Therefore, modafinil is still an agent in search of a mechanism. Several in vivo and in vitro studies suggest that modafinil demonstrates an increase in glutamatergic, noradrenergic and dopaminergic transmission in specific parts of the brain, and also activates histaminergic tuberomammillary nucleus via inhibition of GABA release (MurilloRodriguez et al, 2007, Scammell et al, 2000), which are all known to be involved in pathophysiology of epilepsy. However, its use in epileptic patients is limited due to safety suspicions.

This study aimed to examine the effects of modafinil on behavioural results of PTZ-induced convulsive epilepsy in rats.

\section{Material and methods}

Subjects

Adult male Wistar rats weighting 200-250 g were used throughout this study after at least 1 week of aclimatisation. All described procedures were approved by the local ethics committee. Animals were housed in groups of 3-4 and were allowed free 
access to food and water. All animals were kept in a temperature controlled $\left(22 \pm 1^{\circ} \mathrm{C}\right)$ environment on a 12-h light/dark cycle.

\section{Experimental groups}

Rats were assigned to the following experiment groups and each animal group was composed of seven rats:

Group1: Serum physiologic (SF) (1 week; i.p)

Group 2: $1 \mathrm{mg} / \mathrm{kg} /$ day modafinil (1 week; i.p)

Group 3: $2 \mathrm{mg} / \mathrm{kg} /$ day modafinil (1 week; i.p)

Group 4: $4 \mathrm{mg} / \mathrm{kg} /$ day modafinil (1 week; i.p)

Group 5: $45 \mathrm{mg} / \mathrm{kg}$ /day modafinil (1 week; i.p)

Group 6: $180 \mathrm{mg} / \mathrm{kg} /$ day modafinil (1 week; i.p)

\section{Induction of epileptiform activity}

Seizures were induced by i.p. injection of pentylenetetrazole (PTZ, 80 mg:kg; Sigma St. Louis, MO), 2 hours after the last dose of 1 week modafinil administration. Following PTZ injection, all rats were observed for $30 \mathrm{~min}$ and latency for the onset of first myoclonic jerk (FMJ), latency for the generalized seizures and the total period of generalized seizures were recorded. The intensity of the seizures was scored as follows (Mares et al, 1990):

Stage 0 . No reaction

Stage 0.5. Atypical behaviour

Stage 1. Generalized myoclonic jerk

Stage 2. Atypical minimal seizures

Stage 3. Minimal seizures without loss of rearing reflex

Stage 4. Generalized seizures without tonic phase

Stage 5. Generalized tonic-clonic seizures

\section{Statistical analysis}

All statistical procedures were performed using the SPSS statistical software package (version: 12.0). The differences between the groups were analysed with one-way ANOVA. Significant differences were further evaluated with the Post hoc LSD test. Data are expressed as the means \pm standard error of the mean (SEM). Statistical significance was set at $\mathrm{p}<0.05$.

\section{Results}

Seizure activity was evaluated with the behavioural changes including first myoclonic jerk, sudden muscular spasm accompa-

Tab 1. Comparison of the latencies for the onset of first myoclonic jerk, latencies for the onset of generalized seizure and total period of generalized seizures in the control and modafinil administrated groups. * $\mathbf{p}<\mathbf{0 . 0 5}, * * \mathrm{p}<\mathbf{0 . 0 1}, \Delta$ statistical difference compared to modafinil $1 \mathrm{mg} / \mathrm{kg}(\mathrm{p}<0.05)$.

\begin{tabular}{lccc}
\hline Group (s) & $\begin{array}{c}\text { Latency for } \\
\text { the onset of } \\
\text { first myoclonic } \\
\text { jerk (s) }\end{array}$ & $\begin{array}{c}\text { Latency for } \\
\text { the onset of } \\
\text { generalized } \\
\text { seizure }(\mathrm{s})\end{array}$ & $\begin{array}{c}\text { Total length } \\
\text { of generalized } \\
\text { seizure }\end{array}$ \\
\hline Control & $110 \pm 35$ & $269 \pm 165$ & $1136 \pm 503$ \\
Modafinil $(1 \mathrm{mg} / \mathrm{kg})$ & $122 \pm 81$ & $388 \pm 270$ & $669 \pm 799$ \\
Modafinil $(1 \mathrm{mg} / \mathrm{kg})$ & $200 \pm 59 *$ & $595 \pm 363$ & $437 \pm 527 *$ \\
Modafinil $(1 \mathrm{mg} / \mathrm{kg})$ & $205 \pm 57 * \boldsymbol{\Delta}$ & $483 \pm 234$ & $359 \pm 388 * *$ \\
Modafinil $(1 \mathrm{mg} / \mathrm{kg})$ & $210 \pm 119 * \boldsymbol{\Delta}$ & $436 \pm 324$ & $503 \pm 486 *$ \\
Modafinil $(1 \mathrm{mg} / \mathrm{kg})$ & $194 \pm 63 *$ & $521 \pm 292$ & $200 \pm 355 * *$ \\
\hline
\end{tabular}

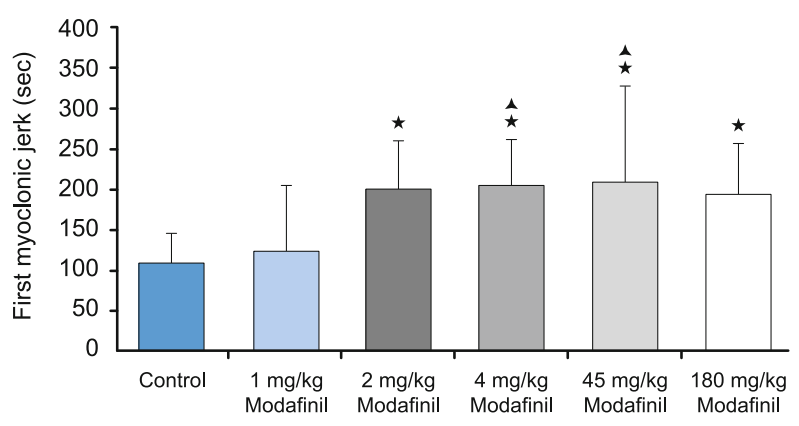

Fig. 1. Comparison of the latencies for the first myoclonic jerks. The latent period of $2,4,45$ and $180 \mathrm{mg} / \mathrm{kg}$ modafinil administrated groups were statistically significant compared to control group $(* p<0.05)$, and also the latent periods of 4 and $45 \mathrm{mg} / \mathrm{kg}$ modafinil administrated groups were statistically significant compared to $1 \mathrm{mg} / \mathrm{kg}$ modafinil administrated group $(\Delta \mathrm{p}<0.05)$.

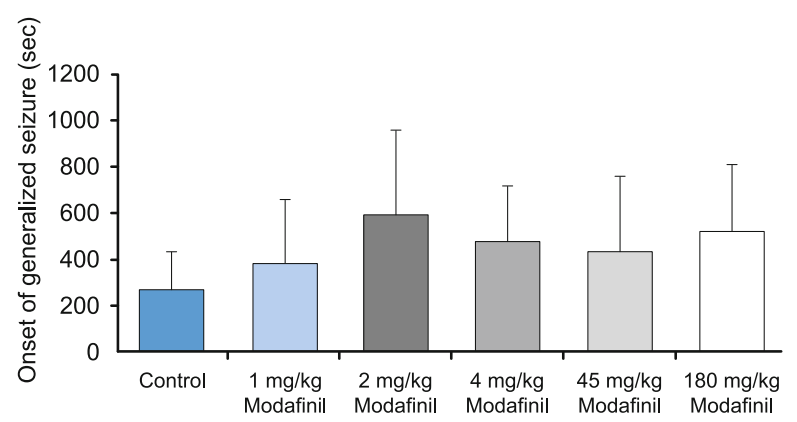

Fig. 2. Comparison of latencies for the generalized seizure onset. There was no statistically difference between any of the groups.

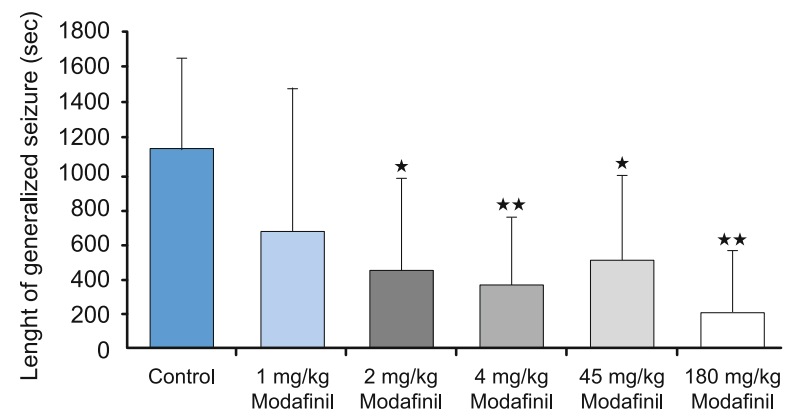

Fig. 3. Comparison of total length of generalized seizures. There was statistically significant difference in $2,4,45$ and $180 \mathrm{mg} / \mathrm{kg}$ modafinil administrated groups compared to the control group $(* \mathbf{p}<0.05$, ** $\mathbf{p}<0.01)$.

nying tail movements and head shivering. The excitation of the anterior and posterior extremities following the clonic jerks with clonus of facial and anterior extremity muscles and also a loss of rearing reflex was determined as the onset of the generalized seizure and the time passed from the onset of generalized seizure to regaining of the rearing reflex was determined as total period of generalized seizure.

Latencies for the onset of first myoclonic jerk; were $110 \pm 35$ sn in the control group and $122 \pm 81 \mathrm{sn}, 200 \pm 59 \mathrm{sn}, 205 \pm 57 \mathrm{sn}$, $210 \pm 119 \mathrm{sn}, 194 \pm 63 \mathrm{sn}$ in the $1 \mathrm{mg} / \mathrm{kg}, 2 \mathrm{mg} / \mathrm{kg}, 4 \mathrm{mg} / \mathrm{kg}, 45$ 
$\mathrm{mg} / \mathrm{kg}$ and $180 \mathrm{mg} / \mathrm{kg}$ modafinil administrated groups; respectively (Tab. 1). The detention of the first myoclonic jerk was statistically significant in 2, 4, 45, $180 \mathrm{mg} / \mathrm{kg}$ modafinil administrated groups, compared to the control group; respectively $(p<0.05)$. Also there was a significant difference in the latencies for the onset of first myoclonic jerks of $4 \mathrm{mg} / \mathrm{kg}$ and $45 \mathrm{mg} / \mathrm{kg}$ modafinil administrated groups compared to $1 \mathrm{mg} / \mathrm{kg}$ modafinil administrated group $(\mathrm{p}<$ 0.05) (Fig. 1).

Latencies for the onset of generalized seizure; were $269 \pm$ $165 \mathrm{sn}$ in the control group and $388 \pm 270 \mathrm{sn}, 595 \pm 363 \mathrm{sn}, 483 \pm$ $234 \mathrm{sn}, 436 \pm 324 \mathrm{sn}$ and $521 \pm 292 \mathrm{sn}$ in the $1 \mathrm{mg} / \mathrm{kg}, 2 \mathrm{mg} / \mathrm{kg}, 4$ $\mathrm{mg} / \mathrm{kg}, 45 \mathrm{mg} / \mathrm{kg}$ and $180 \mathrm{mg} / \mathrm{kg}$ modafinil administrated groups; respectively (Tab. 1). There was no statistically significant difference between any of the groups (Fig. 2) regarding the latencies for the onset of generalised seizures.

Total length of generalized seizures; were $1136 \pm 503 \mathrm{sn}$ in the control group and $669 \pm 799 \mathrm{sn}, 437 \pm 527 \mathrm{sn}, 359 \pm 388 \mathrm{sn}$, $503 \pm 486 \mathrm{sn}, 200 \pm 355 \mathrm{sn}$ in the $1 \mathrm{mg} / \mathrm{kg}, 2 \mathrm{mg} / \mathrm{kg}, 4 \mathrm{mg} / \mathrm{kg}, 45$ $\mathrm{mg} / \mathrm{kg}$ and $180 \mathrm{mg} / \mathrm{kg}$ modafinil administrated groups; respectively (Tab. 1). The reduction in the total period of generalized seizures were found statistically significant in $2,4,45,180 \mathrm{mg} /$ $\mathrm{kg}$ modafinil administrated groups; compared to the control group $(\mathrm{p}<0.05)$ (Fig. 3).

\section{Discussion}

Results of the present study indicate that; modafinil generates a dose depended anticonvulsant effect on PTZ-induced epileptic activity in rats. It is both effective on reducing severity of seizures and extending the latency of the convulsive activity, but it has no effect on the major seizure onset period.

Previous studies indicate that modafinil activates adrenergic and dopaminergic receptors, increases histamin and glutamate release and also inhibits GABAergic activity in different regions of the brain (Chen et al, 2007, Huang et al, 2008, Ishizuka et al, 2003). The role of glutamate, GABA, noradrenalin, dopamine and histamine receptors on patophysiology of epileptogenesis has been investigated for many years (Leurs et al, 1998, Weinshenker ve Szot, 2002). Chen et al (2007); investigated the effects of modafinil ( 22.5, 45, 90 and $180 \mathrm{mg} / \mathrm{kg}$, ip) on PTZ-kindling and maximal electroshock (MES) seizures, they showed that it significantly decreased the incidence of tonic hind leg extension in MES seizure and protected against PTZ induced convulsive behaviours in 22.5, 45 and $90 \mathrm{mg} / \mathrm{kg}$ doses. In addition, modafinil at $180 \mathrm{mg} / \mathrm{kg}$ dose exerted an antiepileptic effect in the MES model, but increased the seizure stage in the PTZkindling model. They also demonstrated that the antiepileptic effect of modafinil was antagonized by the adrenergic $\alpha_{1}$ receptor antagonist in the MES model and by either adrenergic $\alpha_{1}$ and histaminergic $\mathrm{H} 1$ antagonists in the PTZ-kindling model. The anticonvulsant effects of modafinil at low doses (22.5, 45 and 90 $\mathrm{mg} / \mathrm{kg}$ ) presented in this study are compatible with the results of the present study. However, the effects of high dose $(180 \mathrm{mg} / \mathrm{kg})$ of modafinil in PTZ-kindling model is in contradiction with our results. In previous studies, modafinil was shown to modulate noradrenalin transporter (Madras et al, 2006), block noradrenalin re-uptake (Gallopin et al, 2004) and as a result, increase central noradrenergic transmission (Duteil et al, 1990). In many studies adrenergic $\alpha_{1}$ receptor activation was shown to have anticonvulsant effects, whereas $\alpha_{1}$ receptor inhibition is proconvulsant (Chauvel and Trottier, 1986, Weinshenker and Szot, 2002, Wisor and Eriksson, 2005).

It has been suggested that histamin might have a role in termination of epileptic seizures by similar way with opioids (Yokoyama et al, 1992). H1R has been reported to mediate the anticonvulsive effect of histamine (Kamei et al, 1998). H1R antagonists, such as pyrilamine, diphenhydramine, methapyrilene, and chlorpheniramine, are brain-penetrating drugs with sleeppromoting effects and induce seizure in human beings and rats (Kamei et al, 2000), accelerate rat kindling seizures (Yokoyama et al, 1996), and lower the mouse PTZ seizure threshold. Jin et al (2004); investigated the effects of the first-generation H1 receptor antagonist; dipenhydramine and the second generation H1 receptor antagonist; fexofenadine on PTZ-induced kindling seizures. They demonstrated that diphenhydramine significantly enhanced the seizure severity, compared to fexofenadine. They concluded that seizure development of PTZ-induced kindling is promoted by the first-but not the second generation histamine H1 antagonists via the blockade of brain histamine H1 receptor. Modafinil significantly increases histamine release and enhances c-fos immunoreactivity (a gene that is transcribed by the factors that cause growth and differentiation by affecting cells) in the tuberomammillary nucleus (Ishizuka et al, 2003, Scammell et al, 2000). Tuberomamillary nucleus is the neuronal source of histamine and these neurons are essential for wake promoting (Lin et al, 1994). Ishizuka et al. demonstrated that intracerebroventricular injection of modafinil increased histamine levels but direct injection of modafinil to the tuberomamillary nucleus did not stimulate histamin release (Ishizuka et al, 2003). Nishida et al (2007) reported that deep brain stimulation targeted to the tuberomammillary nucleus inhibited PTZ-induced seizure in rats. They also detected that the antiepileptic effect of deep brain stimulation to the tuberomammillary nucleus was also blocked by H1R antagonist. They concluded that; tuberomamillary nucleus; a sole region where cell bodies of the histaminergic neurons are located, activates the histaminergic system and induces desynchronization to inhibit PTZ-induced seizure in rats.

There is lot of evidence that modafinil also enhances dopaminergic transmission by connecting weakly to dopamin carriers (Mignot et al, 1994, Dopheide et al, 2007). Recent studies have shown that dopamine receptor agonists induce expression of Foslike immunoreactivity in rat striatal neurons. Studies carried by using dopamin agonists or drugs which enhance dopaminergic transmission such as amfetamine demonstrated that fos protein levels increased in all regions where modafinil increased c-fos immunoreactivity. (Cole et al, 1992, Wirtshafter, 1998).

Ferraro et al (1996) used dual prob microdialysis method for investigating effects of modafinil on GABA release in 3 different regions of the brain (striatum, globus pallidus ve substansia nigra) and they demonstrated that modafinil decreases GABA released 
in striatal and pallidal regions, but did not affect GABA levels in nigral region. They also showed that modafinil enhances glutamate release in lower regions of thalamus (Ferraro et al, 1998). Previous microdialysis studies using a similar microdialysis preparation in an awake rat have shown that modafinil reduced GABA release in the medial preoptic area and posterior hypothalamus but not in two discrete subregions of the thalamus where conversely the drug enhanced glutamate release (Ferraro et al, 1996). A proton study using two dimensional NMR spectroscopy in the rat has shown that modafinil increased the level of aspartate and the glutamateglutamine pool in the cortex. A complementary microdialysis study has demonstrated the occurrence of a moderate transitory increase, followed by a prolonged decrease, in the level of extracellular glutamate in the rat brain cortex. We can conclude that acute and chronic effects of modafinil on glutamate-GABA balance are different. In the present study, we examined the chronic effects of modafinil after 1 week administration. Accordingly, we can say that the chronic decrease in glutamate levels during the modafinil administration period may be responsible from its antiepileptic effect.

On the other hand, previous laboratory studies have shown that modafinil has antioxidative and neuroprotective effects, which can also be related to its antiepileptic effects. The primary site of action of modafinil's antioxidant effects is unknown, but it is possible to directly act on enzymes in the free radical scavenging system of the brain and reduce free radical levels. Xiao et al (2004) investigated the effects of modafinil on the oxidative stress induced by MPTP exposure in mice brain. They demonstrated that modafinil increased the reduced levels of glutathione and reduced the increased levels of lipid peroxidation products in MPTP damaged neurons. Antonelli et al (1998) showed that modafinil prevented glutamate cytotoxicity in cultured cortical neurons. Modafinil was shown to prevent the reduction in GABA release in the cells exposed to glutamate, but had no effects on GABA levels of the cells not exposed to glutamate. The neuroprotective properties of modafinil may be linked to the prolonged decrease in extracellular glutamate levels. Convulsive epilepsies also cause a similar glutamate cytoxicity and neuroprotective effects of modafinil may be another possible way to prevent these seizures.

According to the data obtained from this study, we can conclude that modafinil is able to increase the seizure threshold and to attenuate the severity of seizures in PTZ induced convulsive epilepsy in rats. We think that, modafinil may be a potential antiepileptic drug in some kinds of epileptic seizures, at least it may increase the effectiveness of the novel antiepileptics or attenuate their side-effects when coadministrated. Further investigations both with animal and human studies are needed to demonstrate the molecular bases of modafinil's antiepileptic effects.

\section{Conclusion}

These results imply that modafinil can show a dose dependent antiepileptic effect on pentylenetetrazol-induced convulsive epilepsy in rats.

\section{References}

1. Artsy E, McCarthy DC, Hurwitz S, Pavlova MK, Dworetzky BA, Lee JW. Use of modafinil in patients with epilepsy. Epilepsy Behav 2012; 23 (4): 405-408.

2. Azuma S, Kodama T, Honda K, Inoué S. State-dependent changes of extracellular glutamate in the medial preoptic area in freely behaving rats. Neurosci Letts 1996; 214: 179-182.

3. Chauvel P, Trottier S. Role of noradrenergic ascending system in extinction of epileptic phenomena. Adv Neurol 1986; 44: 475-487.

4. Chen Cr, Qu Wm, Qiu Mh, Xu Xh, Yao Mh, Urade Y, Huang Z. Modafinil exerts a dose-dependent antiepileptic effect mediated by adrenergic alpha1 and histaminergic $\mathrm{H} 1$ receptors in mice. Neuropharmacology 2007; 53 (4): 534-541.

5. Ciğer A. Epilepsy in adults. Hacettepe University Faculty of Medicine, Neurology, lecture notes. İst, Turkey 2002; 5: 115-118.

6. Cole AJ, Bhat RV, Patt C, Worley PF, Baraban JM. D1 dopamine receptor activation of multiple transcription factor genes in rat striatum. $\mathrm{J}$ Neurochem 1992; 58: 1420-1426.

7. Dalby NO, Mody I. The process of epileptogenesis: a pathophysiological approach. Curr Opin Neurol 2001; 14: 187-192.

8. Disbrow JK, Ruth JK. Differential glutamate release in brain regions of long and short sleep mice. Alcohol 1984; 1: 201-203.

9. Dopheide MM, Morgan RE, Rodvelt KR, Schachtman TR, Miller DK. Modafinil vokes striatal $[(3) \mathrm{H}]$ dopamine release and alters the subjective properties of stimulants. Eur J Pharmacol 2007; 568: 112-123.

10. Duteil J, Rambert FA, Pessonnier J, Hermant JF, Gombert R, Assous E. Central alpha 1-adrenergic stimulation in relation to the behaviour stimulating effect of modafinil; studies with experimental animals. Eur J Pharmacol 1990; 180: 49-58.

11. Ferraro L, Antonelli T, O'Connor WT, Tanganelli S, Rambert FA, Fuxe K. The effects of modafinil on striatal, pallidal and nigral GABA and glutamate release in the conscious rat: evidence for a preferential inhibition of striato-pallidal GABA transmission. Neurosci Lett 1998; 253: $135-138$

12. Ferraro L, Tanganelli S, O'connor WT, Antonelli T, Rambert F, Fuxe K. The vigilance promoting drug modafinil increases dopamine release in the rat nucleus accumbens via the involvement of a local GABAergic mechanism. Eur J Pharmacol 1996; 306: 33-39.

13. Fisher RS. Animal models of epilepsie. Brain Res Rev 1989; 14 : 245-278.

14. G Bambal, D Cakil, F Ekici. Models of experimental epilepsy. J Clin Exp Invest 2011; 2: 118-123.

15. Gallopin T, Luppi PH, Rambert FA, Frydman A, Fort P. Effect of the wake-promoting agent modafinil on sleep-promoting neurons from the ventrolateral preoptic nucleus: an in vitro. Pharmacol Study 2004; 27 (1): 19-25.

16. Goldman H, Berman RF, Hazlett J, Murphy S. Cerebrovascular resonses to pentylenetetrazol: time and dose dependent effects. Epilepsy Res 1992; 12: 227-242.

17. Guyton AC, Hall JE. Textbook of Medical Physiology. Nobel Medical Bookstores, 1st, Turkey 2004; 693-694.

18. Herman ST. Epilepsy and sleep. Curr Treat Options Neurol 2006; 8( 4): 271-279. 
162-166

19. Huang Q, Zhang L, Tang L, Wang L, Wang Y. Modafinil modulates GABA-activated currents in rat hippocampal pyramidal neurons. Brain Res 2008; 1208: 74-78.

20. IA Klioueva, ELJM van Luijtelaar, NE Chepurnova, SA Chepurnov. PTZ-induced seizures in rats: effects of age and strain. Physiol Behav 2001; 72: 421- 426 .

21. Ishizuka T, Sakamoto Y, Sakurai T, Yamatodani A. Modafinil increases histamine release in the anterior hypothalamus of rats. Neurosci Lett 2003; 339: 143-146.

22. Jin CL, Chen Z, Zhang LS, Guo Y, Zhang LY, Yanai K. Effects between the first-and second-generation histamine $\mathrm{H} 1$-antagonists on seizure development of pentylenetetrazole-induced kindling in rats. Zhejiang Da Xue Xue Bao Yi Xue Ban 2004; 33 (3): 209-212.

23. Kamei C, Ishizawa K, Kakinoki H, Fukunaga M. Histaminergic mechanisms in amygdaloid-kindled seizures in rats. Epilepsy Res 1998; 30: $187-194$.

24. Kamei C, Ohuchi M, Sugimoto Y, Okuma C. Mechanism responsible for epileptogenic activity by first-generation $\mathrm{H}_{1}$-antagonists in rats. Brain Res 2000; 887: 183-186.

25. Kayaalp O. Antiepileptic drugs. Rational Treatment in Terms of Medical Pharmacology. 10th ed. 2002: 1008-1010.

26. Leurs R, Blandina $P$, Tedford C, Timmerman H. Therapeutic potential of histamine $\mathrm{H} 3$ receptor agonists and antagonists. Trends Pharmacol Sci 1998; 19: 177-183.

27. Lin JS, Sakai K, Jouvet M. Hypothalamo-preoptic histaminergic projections in sleep-wake control in the cat. Eur J Neurosci 1994; 6: 618-625.

28. Madras BK, Xie Z, Lin Z, Jassen A, Panas H, Lynch L, Johnson R, Livni E, Spencer TJ, Bonab AA, Miller GM, Fischman AJ. Modafinil occupies dopamine and norepinephrine transporters in vivo and modulates the transporters and trace amine activity in vitro. J Pharmacol 2006; 319: 561-569.

29. Mares P, Mirvaldova H, Belska M. Influence of a new antiepileptic drug ORG 6370 on metrazol-induced seizures in rats during ontogenesis. Physiol Bohemoslov 1990; 39 (3): 199-205.

30. Mignot E, Nishino S, Guilleminault C, Dement WC. Modafinil binds to the dopamine uptake carrier site with low affinity. Sleep 1994; 17: 436-437.
31. Murillo-Rodriguez E, Haro R, Palomero-Rivero M, Millan-Aldaco D, Drucker-Colin R. Modafinil enhances extracellular levels of dopamine in the nucleus accumbens and increases wakefulness in rats. Behav Brain Res 2007; 176: 353-357.

32. Nishida N, Huang ZL, Mikuni N, Miura Y, Urade Y, Hashimoto N. Deep brain stimulation of the posterior hypothalamus activates the histaminergic system to exert antiepileptic effect in rat pentylenetetrazol model. Exp Neurol 2007; 205: 132-144.

33. Onat F. Experimental models of epilepsy. Epilepsy. Nobel Medical bookstores, 1st, Turkey 2008; 4: 37-43.

34. Scammell TE, Estabrooke IV, McCarthy MT, Chemelli RM, Yanagisawa M, Miller MS, Saper CB. Hypothalamic arousal regions are activated during modafinil-induced wakefulness. J Neurosci 2000; 20: 8620-8628.

35. Sridharan R. Epidemiology of epilepsy. Curr Sci 2002; 82: 664-670.

36. Velisek L, Kusa R, Kulovana M, Mares P. Excitatory amino acid antagonists and pentylenetetrazol-induced seizures during ontogenesis: I. The effects of 2-amino-7-phosphonoheptanoate. Life Sci 1990; 46: 1349-1357.

37. Weinshenker D, Szot P. The role of catecholamines in seizure susceptibility: new results using genetically engineered mice. Pharmacol Ther 2002; 94: 213-233.

38. Wirtshafter D. D1 dopamine receptors mediate neuroleptic induced Fos expression in the islands of Calleja. Synapse 1998; 28: 154-159.

39. Wisor JP, Eriksson KS. Dopaminergic-adrenergic interactions in the wake promoting mechanism of modafinil. Neuroscience 2005; 132 : 1027-1034.

40. Yokoyama H, Iinuma K. Histamine and seizure: implications for the treatment of epilepsy. CNS Drugs 1996; 5: 321-330.

41. Yokoyama H, Onodera H, Maeyama K et al. Histamine levels and maximal electroshock seizure in mice: The effects of an a-fluoromethylhistidine and metoprine. Naunyn-Schmiedeberg's Arch Pharmacol 1992; 346: $40-45$.

42. Ziylan YZ. Nervous System. Control Systems, Digestive and Urinary Physiology. Nobel Medical Bookstores, 1st, Turkey 2001: 316-317.

Received October 21, 2013. Accepted November 4, 2013. 